\title{
Software development for Course and Program Outcome attainment
}

\author{
D.R.Kalbande ${ }^{1}$, S.S.Rathod ${ }^{2}$ \\ ${ }^{1}$ Professor and Head,Computer Engineering, \\ ${ }^{2}$ Professor and Head, Electronics Engineering \\ Sardar Patel Institute of Technology, Munshi Nagar, Andheri (W), Mumbai-400058 \\ ${ }^{1}$ drkalbande@spit.ac.in \\ ${ }^{2}$ surendra_rathod@spit.ac.in
}

\begin{abstract}
In today's competitive world, every institute needs to keep their academic standard as high as possible. It becomes mandatory for all most all the institutes to maintain the quality in technical education as well as to produce the skilled graduates. In order to produce the skill graduates, the Institute always rely on different programs which is responsible for producing the high calibre graduate. As of now, there is no such application available which will automate at least the process of reducing the clerical work required for preparing the course file to evaluate the Course Outcome with Program Outcome .NBA has laid down the guidelines for each program through the means of rubrics to undergo this evaluation process which implies the accreditation grade to be given from NBA committee. This application allows the faculty to enter the details about their courses in terms of mapping with PO, PSO and Bloom's Taxonomy. The application calculates the PO attainment which helps the faculty about the existing gap which further can be improved in the next semester.Hence such type of application will assist the faculty to reduce their workload regarding the individual course.
\end{abstract}

Keywords: CO, PO,PSO,ABET, NBA,Bloom's

\section{D.R.Kalbande ${ }^{1}$}

${ }^{1}$ Professor and Head,Computer Engineering,

Sardar Patel Institute of Technology, Munshi Nagar, Andheri (W), Mumbai-400058

${ }^{1}$ drkalbande@spit.ac.in

\section{Introduction}

The Bachelor of Engineering program has some educational objectives. These educational objectives are the long term goals that program set for students. These programs prepare students to achieve these objectives four to five years after graduation.

The Course outcome (CO) are the statements that describe desired learning that learners have achieved, and can be demonstrate at the end of a course. In other words, course outcomes describe what students should determine upon the completion of a course.[6].All courses in a particular program would have their own course outcomes These course outcomes are designed based on requirement of the program outcomes[6] and program specific outcomes. Each course outcomes are mapped to Program outcomes and program specific outcomes.

The program outcomes $(\mathrm{PO})$ are clear, concise statements that describe how students can demonstrate the skills obtained at the end of their graduation. Program outcomes are based on the twelve Graduate Attributes(GA's) defined by NBA[6].

The program specific outcome(PSO) are the statements that describe the skill attainment of the graduate specific to the program of study. For example, one of the PSO for Computer Engineering Undergraduate program can be - Developed software application to solve real life problem'.

There are two assessment methods, Direct and Indirect Assessment Method.

Direct Method display the student's knowledge and skills from their performance in the continuous assessment tests, end semester examination, presentation and classroom assignments etc. These methods provide a sampling of what students know and / or can do and provide strong evidence of student leanring.[6]

Indirect Method gives information about graduate's perception of their learning and how this learning is valued 
by different stakeholders. For example, course exit survey is one of the indirect assessment tool.

The course and program outcome (CO-PO) assessment template includes all data of tests, labs, assignments, course exits and exams imported from an instructor's course file. The application facilitates evaluation process or rubrics for all courses and instructors; additionally, it also assists the instructor to understand the highlights and drawbacks in achievement of course outcomes and program outcomes and to make the necessary changes to improve them.

\section{Litrature Review}

HosseinRahemi, Naveen Seth [1] has discussed about the implementation of an assessment process that will measure student-learning outcomes and develop a model for a continuous improvement process that will ensure student success. Suseel K Pallapu[2] has discussed the process of automating outcome-based assessment, where an existing course in BalckBoard is exported into TrueOutcomes. Said Elnaffar, Adnan Harb, EmadEldin Mohamed [3] has introduces iAssess; a system that automates the course assessment process. iAssess serves two purposes. First, it eases the assessment process to make it practical. Second, it provides more accurate and clearer feedback that helps improve the course delivery. This paper focuses on course assessment as an indispensable instrument that is widely used inside any college.

In 1956, Benjamin Bloom [4] headed a group of educational psychologists who developed a classification of levels of intellectual behavior important in learning. This became a taxonomy including three overlapping domains; the cognitive, psychomotor, and affective. Each of the domains can be utilized through the interaction of media.

Cognitive learning is demonstrated by knowledge recall and the intellectual skills: comprehending information, organizing ideas, analyzing and synthesizing data, applying knowledge, choosing among alternatives in problemsolving and evaluating ideas or actions. This domain on the acquisition and use of knowledge is predominant in the majority of courses. Bloom identified six levels within the cognitive domain, from the simple recall or recognition of facts, as the lowest level, through increasingly more complex and abstract mental levels, to the highest order which is classified as evaluation. Verb examples that represent intellectual activity on each level are listed here.

Knowledge: The recall of specifics, universals, methods, processes, or patterns. Remembering. Arrange, define, duplicate, label, list, memorize, name, order, recognize, relate, recall, repeat, reproduce state.

Comprehension: The person "knows" the material and can use it but cannot relate it to other material or see its broader implications. The lowest level of understanding. Classify, describe, discuss, explain, express, identify, indicate, locate, recognize, report, restate, review, select, translate,

Application: The use of abstractions (e.g., principles, ideas, theories) in particular and concrete situations. Apply, choose, demonstrate, dramatize, employ, illustrate, interpret, operate, practice, schedule, sketch, solve, use, write.

Analysis: The breakdown of a communication into its constituent elements such that the relations among the ideas is made explicit. Analyze, appraise, calculate, categorize, compare, contrast, criticize, differentiate, discriminate, distinguish, examine, experiment, question, test.

Synthesis: Working with parts and combining them in such a way as to constitute a structure. Arrange, assemble, collect, compose, construct, create, design, develop, formulate, manage, organize, plan, prepare, propose, set up, write.

Evaluation: Judgments about the value of material and methods for given purposes. Appraise, argue, assess, attach, choose compare, defend estimate, judge, predict, rate, core, select, support, value, evaluate.

Accreditation board for Engineering and Technology (ABET) [5] made it mandatory for universities to follow the outcome based assessment and evaluation process for accreditation purpose. National Board of Accreditation, India (NBA) [6] has also introduced a new process, parameters and criteria for accreditation. These are in line with the best international practices and oriented to assess the outcomes of the programme.

\section{Proposed System}

The following Fig. 1 explains the general flow of the steps involved in evaluation of course and program outcomes. 


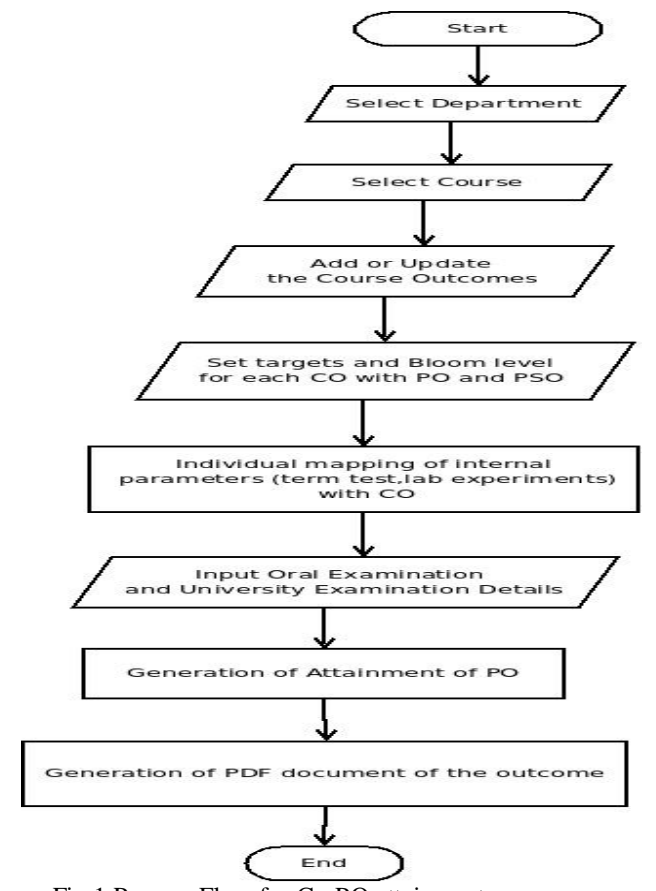

Fig.1 Process Flow for Co-PO attainment

Initially the instructor selects the department and enters the course details with course outcomes. The mapping of each course outcome is done with program outcome along with the attainment levelof PO, PSO and Bloom's Level. Then individual mapping of each course outcome $(\mathrm{CO})$ with internal term tests, laboratories, course exit etc are done. Therubrics are then generated for each PO and PSO. The faculty can then view the pdf document of the course for self-evaluation.

The actual working model is described with each step explained in above process as follows:(Fig 2 to 13).

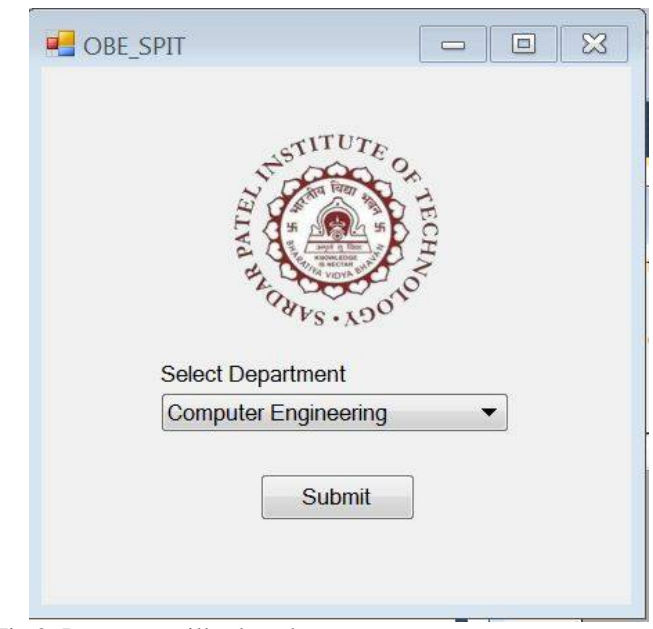

Fig.2. Instructor will select department
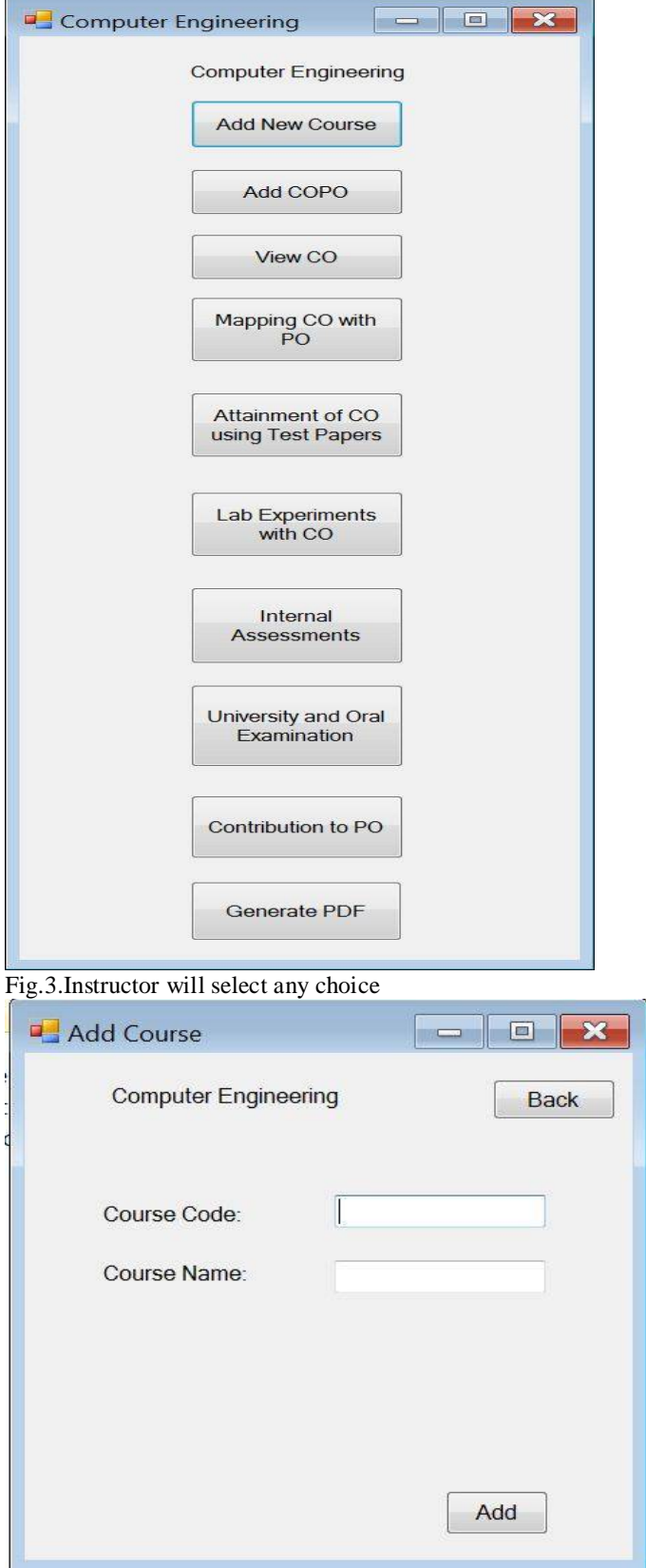

Fig.4 Instructor will add course 


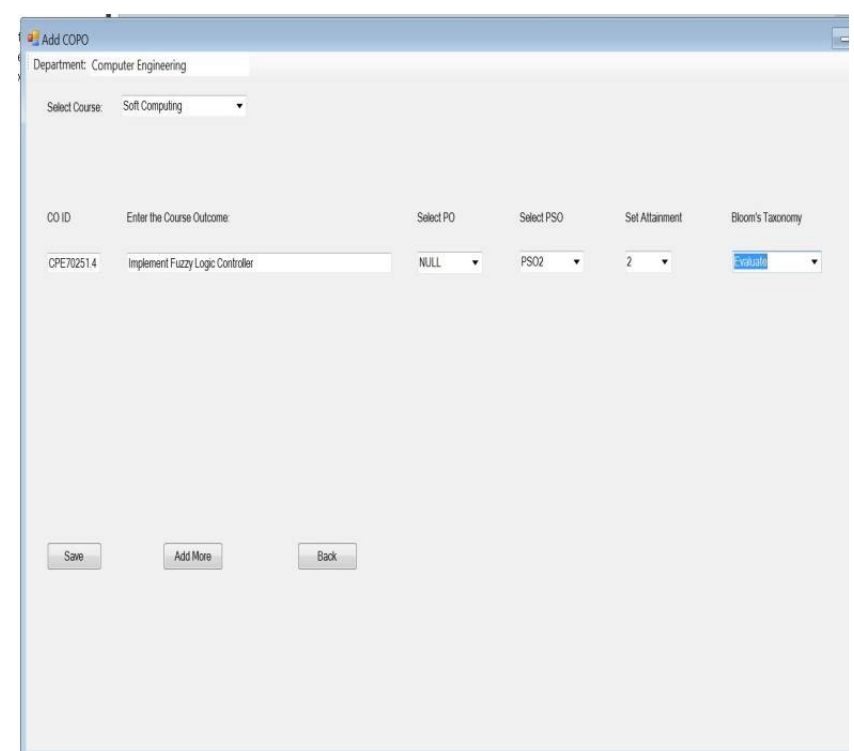

Fig.5 Instructor will add $\mathrm{CO}$ along with the mapping with PO/PSO and Bloom's level

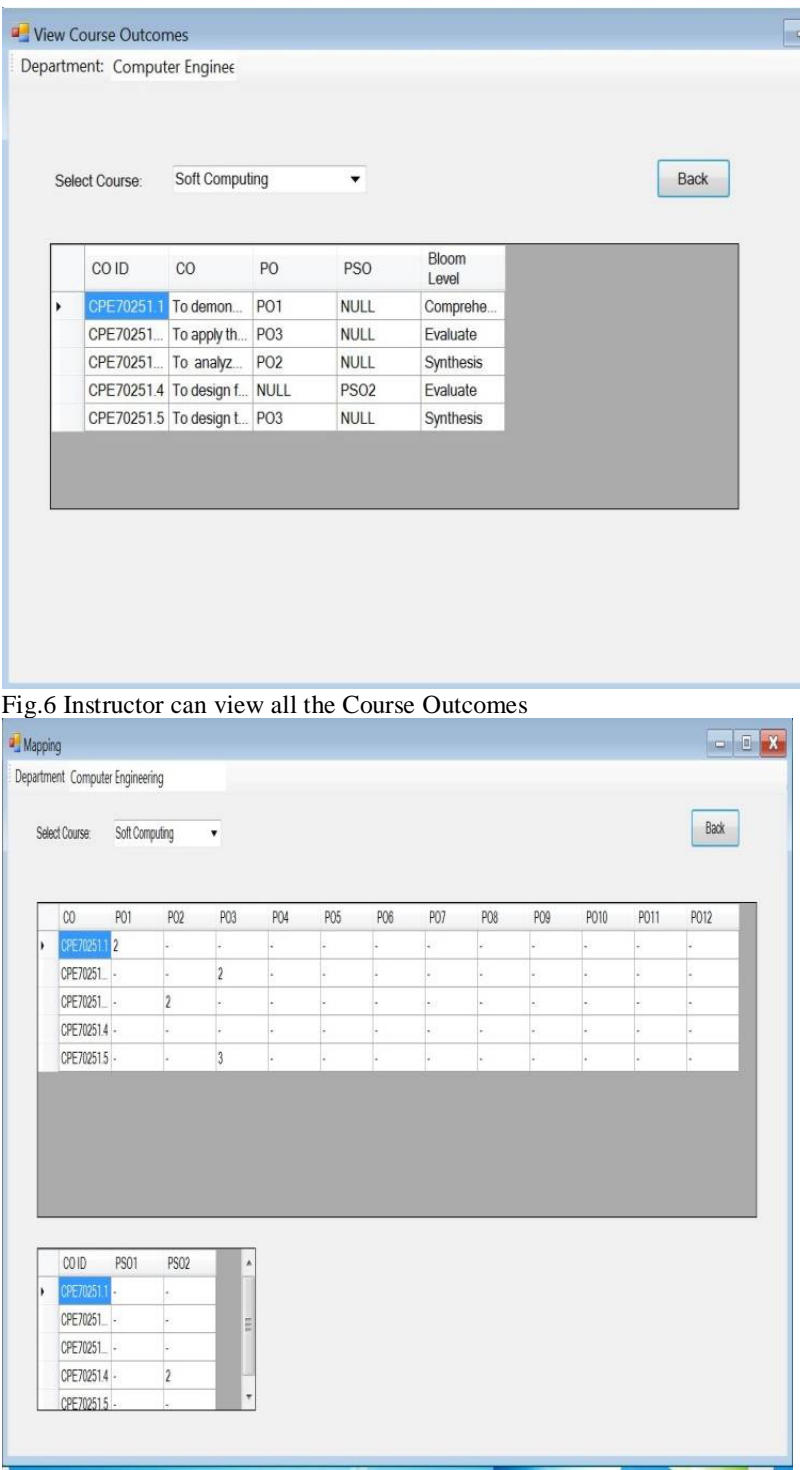

\section{JEË}

Fig.7 Instructor can view the mapping of the $\mathrm{CO}$ with the PO/PSO

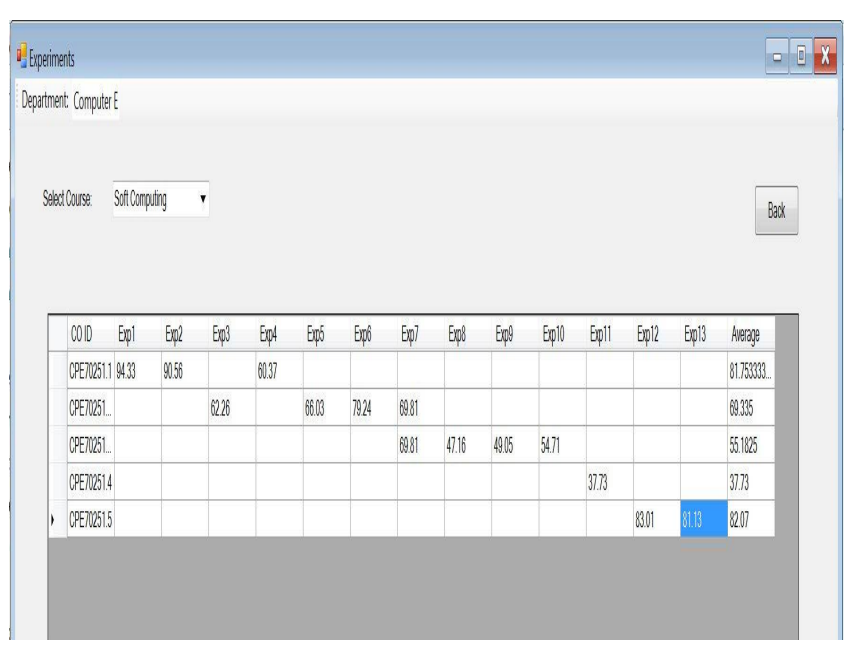

Fig.8 Instructor enters individual laboratory experiments contribution towards each course outcome.

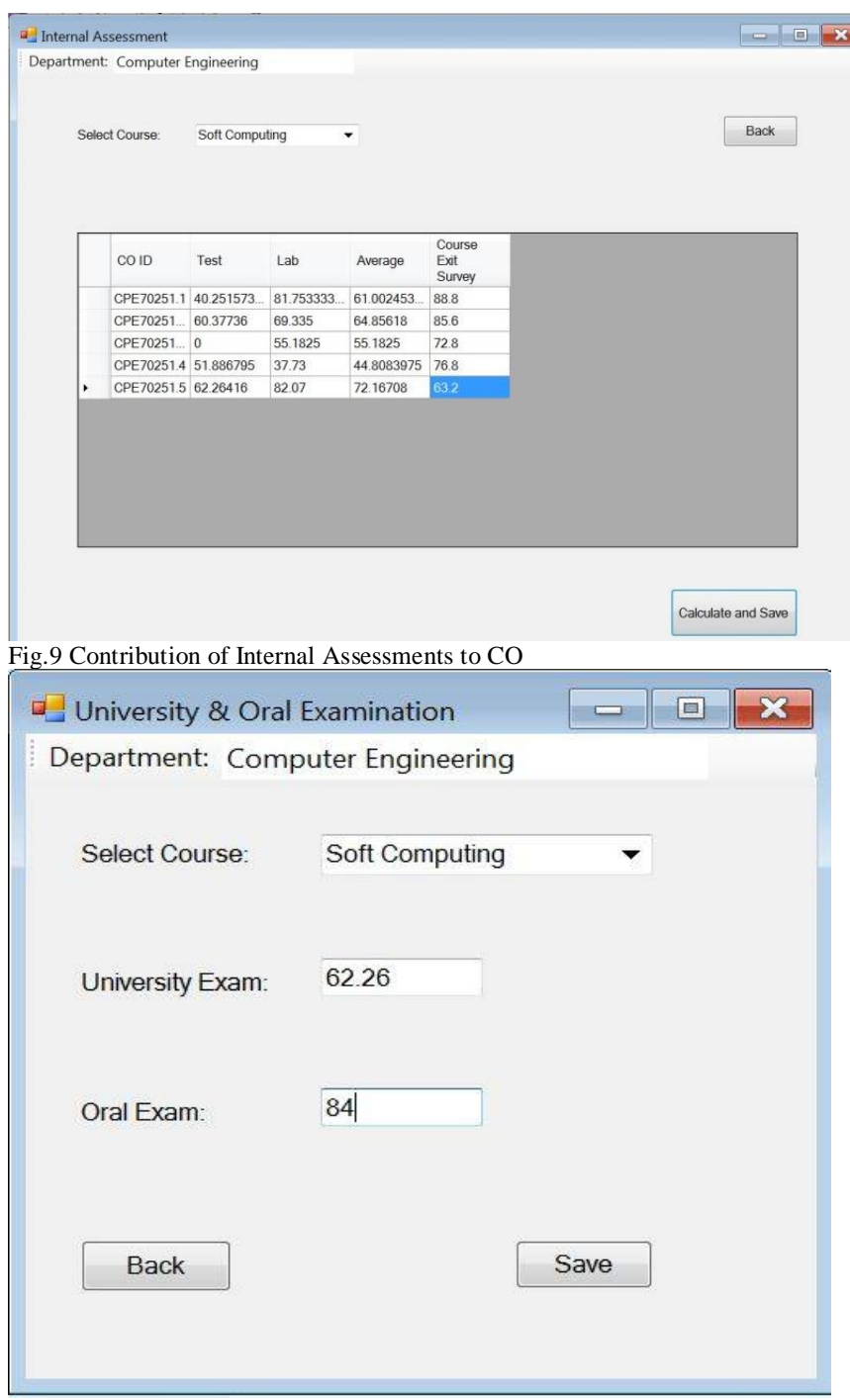

Fig.10 Instructor enters the contribution of University Exam and Oral Exam towards course outcome. 


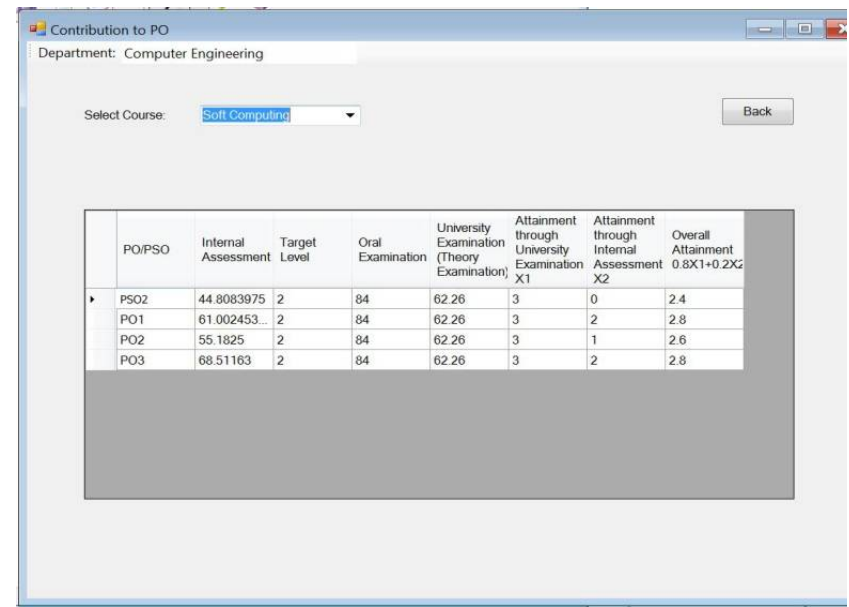

Fig.11 Final contribution towards PO

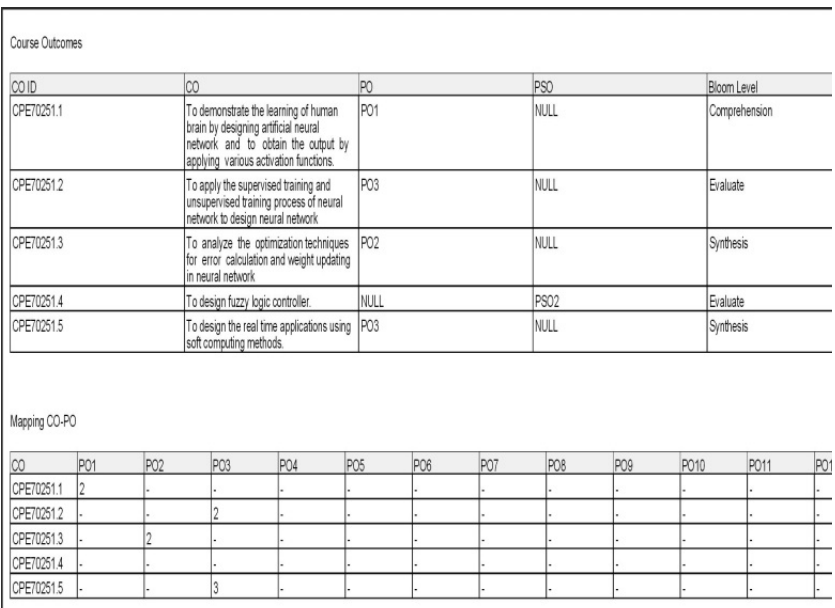

Fig.12 Final PDF Generated

\begin{tabular}{|c|c|c|c|c|c|c|c|c|c|c|c|c|c|c|}
\hline CPE7025 & P01 & P02 & PO3 & POP & PO & PO: & PO\& & POS & POP & PO & PS & S PSO2 & PS03 & PS04 \\
\hline Target & 2 & 2 & 25 & . & - & - & - & & . & - & & 2 & - & - \\
\hline Direct Method (Y1) & 28 & 2.6 & 28 & - - & - & - & - & - & - & - & & 24 & - & - \\
\hline Indrect Method (Y2) & 3 & 3 & 2 & - . & $\cdot$ & & & & . & - & & 2 & & \\
\hline Attainment & 284 & 2.68 & 264 & $\cdots$ & - & - & - & & - - & - & & 2.32 & - & - \\
\hline & & & & $e_{1}$ & i & & & & 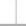 & & & & & \\
\hline
\end{tabular}

Fig.13 Final PDF Generated (Continued from Fig.12.)

\section{Conclusions}

The application allow the instructor to identify the weaker elements of the course outcomes and bring the necessary changes to improve them further. The application can be used as an effective tool for self-assessment of courses.

\section{References}

1. HosseinRahemi1 , Naveen Seth 2 , "Student Learning Outcomes: An Integrated Continuous Improvement Process for Course and Program Assessment", Latin American And Caribbean Journal Of Engineering Education, Vol. 2(2), 2008 .
2. Suseel K Pallapu Automating Outcome based Assessment ,Arizona State University Polytechnic,(East),Conference '05,January 3-6,2005,Island of Hawaii,USA,Copyright 2004, ACM.

3. Said Elnaffar, Adnan Harb, EmadEldinMohamed, Automating Course Assessment: the iAssess System, IEEE International Conference on Teaching, Assessment and Learning for Engineering (TALE), 26-29 August 2013, Bali Dynasty Resort, Kuta, Indonesia 2013.

4.Bloom's Taxonomy from DLRN Technology Resource Guide, Chapter 4 available at http://www.csun.edu/ hflrc001/bloom.html .

5.www.abet.org

6.www.nbaind.org

Authors Biography

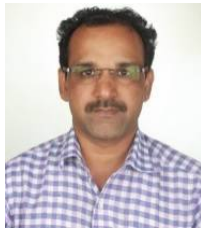

D. R. Kalbandeis currently a Professor and Head in Department of Computer Engineering, Sardar Patel Institute of Technology, Andheri (West),Mumbai, India. He has completed B.E. in Computer Technology, Master of Engineering in Information Technology and obtained Ph.D from University of Mumbai, Mumbai in 2011.He has over 16+ Years experience in teaching \&research.He is recognized as Ph.D. guide in Mumbai and Nagpur University.Currently guiding 6 research scholar in the area of Soft Computing, Mobile Cloud Computing and Imaging Analysis.His area of interest is Soft Computing, Human Computing Interaction, Mobile device applications and Decision making etc.He has authored the two books namely GUI and MIS.He has delivered and conducted the workshop plus seminar talk on Neural Network \& Fuzzy Logic, dot Net. Outcome based accreditation process for Engineering Institutes.He has more than 42 papers published in International conference and journals.

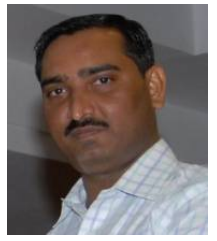

S. S. Rathod received Ph.D. from I.I.T. Roorkee. $\mathrm{He}$ is Professor and Head of Electronics Engineering Department at Sardar Patel Institute of Technology Mumbai. He has 18 years of teaching experience. His special fields of interest include VLSI design, device modeling and circuit 
simulation. He is recognized Ph.D. guide of Mumbai University.

He has published more than 50 papers in various national and international conferences and published twenty papers in international journals like journal of applied physics, IEEE transactions on electron devices, Elsevier microelectronics reliability, IET circuit's devices and systems, ASP journal of low power electronics etc. He is reviewer of IEEE transactions on Electron Devices, Elsevier Microelectronics Journal, Microelectronics Reliability, Academic Journal of Electrical and Electronics Engineering Research, Emrald International Journal of Electronics, Journal of scientific research and review, and several national and international conferences.

Three times he received best paper awards. He received outstanding achievement award (2007) by the Energy Society of India from Governor of Pondicherry. He received "ISTE Best Engineering College Teacher Award for Maharashtra State" in year 2012. He has delivered talks at several engineering colleges on 'outcome based education'. 